\title{
Knowledge and preventive practices towards Covid- 19 and associated factors among healthcare workers in selected health facilities of Illu Aba Bor and Buno Bedelle Zones, Southwest Ethiopia
}

Dereje Tsegaye ( $\nabla$ deretsegaye@gmail.com )

Ragon Institute https://orcid.org/0000-0001-7358-5423

Muluneh Shuremu

Mettu University

Dereje Oljira

Mettu University

Sileshi Dubale

Mettu University

Getachew Befekadu

Mettu University

Kebebew Bidira

Mettu University

Research article

Keywords: Knowledge, practice, COVID-19, health care workers, Ethiopia

Posted Date: September 29th, 2020

DOI: https://doi.org/10.21203/rs.3.rs-49537/v2

License: (c) (i) This work is licensed under a Creative Commons Attribution 4.0 International License.

Read Full License 


\section{Abstract}

Background: The COVID-19 outbreak has been declared a public health emergency of international concern. As the virus is transmitted through close contact and droplets, frontline HCWs caring for COVID19 patients are at risk of the infection. This study aimed at assessing knowledge and preventive practices towards Covid-19 among health care providers in selected health facilities of Illu Aba Bor and Buno Bedele zones, Southwest Ethiopia.

Methods: An institution-based cross-sectional study was conducted from April to May 2020 among 330 health workers in selected health facilities of Illu Aba Bor and Buno-Bedelle Zones, Southwest Ethiopia. Data were collected using a self-administered structured questionnaire. The collected data were entered onto Epidata version 3.1 and exported to SPSS version 23 for analysis. Bivariate and multivariable logistic regression analysis was used to identify independent predictors of preventive practices towards Covid-19. Statistical significance was declared at a p-value of $<0.05$.

Result: Greater part (93.3\%) of the respondent demonstrated good knowledge towards COVID-19 and the mean $( \pm S D)$ knowledge score was $9.04 \pm 1.06$. Nearly two-thirds $(64.2 \%)$ of the study participants had good infection prevention practices. Being male (AOR=3.65, 95\% Cl: $(1.96,6.80))$, education level $(A O R=1.82,95 \% \mathrm{Cl}(1.02,3.22))$, profession (AOR=3.17, 95\% $\mathrm{Cl}(1.08,9.33))$, service year $(5-10$ years) $(A O R=2.00(1.02,3.92))$ and more than 10 years $(A O R=3.14(1.51,6.52))$, availability of personal protective equipment $(\mathrm{AOR}=1.96(1.06,3.61))$ and Knowledge level $(\mathrm{AOR}=2.61(1.48,4.62))$ were independent predictors of COVID-19 preventive practices.

Conclusion: The overall level of knowledge of HCWs was good. However, the practice was relatively low. Gender, educational status, profession, year of service, knowledge towards COVID-19, and availability of personal protective equipment were independent predictors of good infection prevention practices. Optimizing the infection prevention and control loop of the health facilities is recommended.

\section{Background}

Novel-coronavirus (COVID-19) disease is currently a worldwide health threat and public health emergency of global concern(1). The outbreak was first reported in late December 2019 in Wuhan of China, Hubei Province, when groups of pneumonia cases of unknown etiology were found to be associated with epidemiologically linked exposure to the seafood market and untraced exposures(2)

According to the World Health Organization (WHO) daily situation report, after the coronavirus disease 2019 outbreak, 22,073 COVID-19 cases have been reported to the WHO as of April 2020 among healthcare workers (3). As of early March, this number increased to 3,300 and at least 22 died in China, over 2,600 infected with 13 deaths in Italy $(4,5)$. Though the disease was initially slow to reach African countries, it is currently rising exponentially on the continent and is likely to cause severe illness and deaths(6). In Ethiopia, there have been 35 confirmed COVID-19 cases since the first case on 13 March 2020 and the number increased to 117, as of April 24, $2020(7,8)$. 
According to the available evidence, the virus is transmitted from an infected person to another person through close contact and droplets, and therefore those most at risk of infection are frontline health care workers(HCWs) caring for COVID-19 patients $(9,10)$.

Evidence shows that proper infection prevention and control (IPC) measures during outbreak management could change the course of the outbreak(11). However, the current IPC behaviors are far from optimal. A study on the Lassa Fever outbreak among Health care workers (HCWs) showed that none of the study participants met the minimum standards of infection prevention practices during the first contact with fever cases (12). Infection prevention and control behaviors are influenced by factors such as the occurrence of an epidemic, contact with confirmed and suspected cases, key clinical departments (such as intensive care unit and emergency department) that are critical risk factors in the pandemic outbreak and always cited as important causes of high healthcare-associated prevalence worldwide(1315). years of experience and preparedness are other factors associated with healthcare workers' infection prevention and control behaviors(14).

Owing to the current pandemic, an urgent interim guidance document was issued by the World Health Organization (WHO) which underscores the importance of proper sanitation and waste management practices for COVID-19 in health-care settings (16). The guideline builds on and further emphasizes the existing standard infection prevention and control guidelines for health facilities $(17,18)$.

Frontline Healthcare workers are at an increased risk of acquiring the virus owing to overcrowding and lack of sanitary facilities which may be compounded by inadequate awareness of some healthcare workers. To the best literature search, few studies were conducted on the level of awareness and infection prevention practice of healthcare workers. Thus, this study aimed at assessing health care workers' selfreported knowledge and infection prevention practices towards the COVID-19.

\section{Methods}

\section{Study setting and design}

This institution based cross-sectional study was conducted in selected public health facilities in Ilu Abba Bor and Buno Bedelle Zones, Oromia Regional State, southWest Ethiopia. Ilu Abba Bor zone and Buno Bedelle Zone are out of the 20 zones of Oromia regional state situated in the southwest of the region and located at a distance of about $600 \mathrm{~km}$ and 483 from the center of the region respectively. They cover the western part of the region and lies between $34^{0} 52^{\prime} 12^{\prime \prime} \mathrm{E}$ to $41^{0} 34^{\prime} 55^{\prime \prime} \mathrm{E}$ longitudes and $7^{0} 27^{\prime} 40^{\prime \prime} \mathrm{N}$ to $9^{0}$ 02' 10" N latitude. Illu Aba Bor Zone has one town administration and fourteen rural districts with a projected total population of $1,606,502$. One referral and District hospital are found in the zone serving a population of the zone. Buno Bedelle Zone has one town administration and fourteen rural districts with a projected total population of 815,437 . The zone has three functional hospitals and one under construction, 32 health centers, and 246 health posts. The study was conducted from April $27-$ May 10, 2020. 


\section{Population}

All health care providers working in service delivery units in selected health facilities in both Illu Aba Bor and Buno Bedelle Zones were the study population.

\section{Sample size determination and sampling techniques}

The sample size was determined by using single population proportion formula: $n=(Z a / 2)^{2} p(1-p) /(d)^{2}$, where $n$ denotes the sample size, $\mathrm{Za} / 2$ is the reliability coefficient of standard error at $5 \%$ level of significance $=1.96,(5 \%)$ margin of error tolerated, $p=$ proportion of good preventive practice of COVID-19 ( $50 \%$, since there was no previous study available). Hence, the final sample size calculated was 345 after adjusting for the total health worker population in the two Zones. Finally, all health care workers in the selected health facilities were included.

\section{Data collection tools and procedures}

A self-administered structured questionnaire adapted from WHO resources and a review of relevant literature was used to collect the data $(10,19,20)$. The questionnaire was first prepared in English, then translated to the local language (Afan Oromo) and translated back to English by another person who was blinded to the English version to ensure its consistency. The tool was pretested on $5 \%$ of the sample selected from health facilities in Illu aba Bor Zone that were not included in the main study and modified based on the pretest observations. The facilitators were given intensive training for two days before the actual data collection.

The knowledge questions had 12 items covering issues such as COVID-19 symptoms, risk conditions, prognosis, modes of transmission and safety, and precautions. The knowledge score was converted into tertile and the highest tertile was used to define "good knowledge", while the two lower tertiles combined were labeled as "poor knowledge".

The infection prevention practice was assessed using 16 items. The practice was computed by adding the responses, scoring one for each correct answer, and zero otherwise. The practice score was converted into tertile and the highest tertile was used to define "good practice", while the two lower tertiles combined were labeled as "poor practice".

\section{Data processes and Analysis}

Data were entered onto EpiData version 3.1.0 to control skip patterns and allow double entry and exported to SPSS version 23 for analysis. Recoding, transforming, and re-categorization of some variables were performed to compute some of the analyses. In all analyses of the data, a two-sided pwas used. Independent sample t-test and one-way analysis of variance (ANOVA) were performed in 
assessing any difference in mean knowledge score by demographic characteristics. Binary and multivariable logistic regression analyses were computed to examine the association between dependent and independent variables. Odds ratio with a 95\% confidence interval was used to identify the factors associated with good infection prevention and control practices. Multicollinearity between different predictor variables was assessed. Adequacy of the model was checked using the Hosmer and Lemeshow test for goodness of fit.

\section{Results}

\section{Socio-Demographic Characteristics of the respondents}

A total of $330 \mathrm{HCWs}$ were included in the study making the response rate $95.7 \%$. More than half (56.1\%) of the respondents were between 25 - 34 years of age. Two hundred and three (61.5\%) were male participants. More than two-thirds $(69.4 \%)$ of the respondents were married. Nearly half $(47.6 \%)$ were protestant by religion and Oromo is the dominant ethnic group (87.9\%). More than half $(53.7 \%)$ of the respondents were degree holders. One hundred eighty-four (55.8\%) of the HCW were nurses and $108(40.3 \%)$ had less than five years of experience (Table.1).

\section{Training and availability of hygiene facilities}

The study revealed that more than half (59.1\%) of the study participants did not receive training related to infection prevention. One hundred seventy-seven (53.6\%) of the study participants reported that the institution does not have an infection prevention program and 201(60.9\%) did not have an active infection prevention team. More than half (54.5\%) reported that the institution does not have an emerging infectious disease taskforce (dealing with outbreaks) and infection prevention and control guidelines. Nearly two-thirds $(65.8 \%)$ and $54.5 \%$ of the health workers reported the availability of water and soap at their work unit respectively. Three-fourth $(75.2 \%)$ and two-thirds of the respondents reported the availability of alcohol or hand sanitizer and adequate availability of the necessary personal protective equipment (PPE) at their facility respectively. One hundred ninety $(42.4 \%)$ of the respondents reported the availability of colored dust bin to segregate medical wastes at their work unit. One hundred twenty-eight (38.8\%) of the health workers reported that their place of assignment at the time of data collection was at the outpatient department (Table 2).

\section{Knowledge towards COVID-19}

Greater part (93.3\%) of the respondent demonstrated self-reported good knowledge towards COVID-19 and the mean $( \pm S D)$ knowledge score was $9.04 \pm 1.06$. Three hundred twenty-two (97.6\%) correctly answered the mode of transmission of the virus. Almost all (97\%) of the respondents correctly answered that COVID- 19 is a viral infection and (97.9\%) answered that fever, cough, sore throats, and shortness of breath are common symptoms of COVID-19. More than $90 \%$ of HCPs were well aware of the route of 
transmission of the virus. A similar proportion was also aware that frequent handwashing with soap and water or alcohol-based hand rub, and using face masks can help in the prevention of disease transmission. Three hundred and eleven(94.2\%) reported that healthcare workers are at a higher risk of the infection. Two hundred ninety-one (88.2\%) of the respondents correctly identified the isolation period to be 2 weeks. More than three-fourth (79.7\%) answered that there is no vaccine available against COVID-19 and (76.1\%) stated COVID-19 could be fatal. Less than three-fourth (70.3\%) of the respondents indicated antibiotics are not a first-line treatment for the disease (Table 3).

Infection prevention practice

A summary score was developed from continuous data of the practice of healthcare workers regarding infection prevention towards COVID-19. The mean ( \pm SD) self-reported infection prevention practice was $10.05 \pm 4.81$. The overall self-reported good infection practice score towards COVID-19 among the healthcare workers was $64.2 \%$ (Figure 1).

\section{Perceived barriers to infection prevention and control practices}

A mixed perception was reported by HCWs regarding barriers to infection prevention and control practices. Ninety-eight $(29.7 \%)$ of the HCWs presumed that overcrowding in the emergency room was a barrier whereas, $26.7 \%$ strongly agreed that insufficient training on infection prevention was a barrier towards infection prevention and control practices. A quarter $(25.8 \%)$ of the participants strongly agreed that the limitation of infection prevention material was a barrier to infection prevention practices (Figure. 2).

\section{Differences in knowledge among HCPs towards COVID-19}

Independent sample t-test and one-way ANOVA analysis were done to assess the mean knowledge difference between groups regarding socio-demographic characteristics. In both tests, knowledge did not differ significantly $(P>0.05)$ with age, gender, education, experience, or profession (Table 4).

\section{Factors associated with infection prevention practice}

On multivariable logistic regression analysis, gender, educational status, profession, years of service, knowledge towards COVID-19, and availability of personal protective equipment were significantly associated with good infection prevention practices. Accordingly, male HCWS were more than three times to practice good infection prevention than female health care workers (AOR=3.65, 95\% $\mathrm{Cl}:(1.96,6.80)$ ). Bachelor degree holders were about two times more likely to practice good infection prevention compared to diploma holders (AOR=1.82, 95\% $\mathrm{Cl}(1.02,3.22)$ ). Physicians were 3.17 times more likely to practice infection prevention than nurses (AOR=3.17, 95\% $\mathrm{Cl}(1.08,9.33))$. Service year was another factor significantly associated with infection prevention practice. Healthcare workers having service year of 5-10 years were 2 times more likely to have good infection prevention practice (AOR=2.00 $(1.02,3.92))$ and those who have served for more than 10 years were 3.14 times more likely to have good infection prevention practice $(A O R=3.14(1.51,6.52))$ compared to those who have served for less than five years. 
Health care workers who had enough supply of the personal protective equipment at their work unit were 2 times more likely to have good infection prevention practices compared to those who did not have enough supply of the PPE(AOR=1.96 (1.06, 3.61)). The knowledge level of health care workers was significantly associated with good infection prevention practices. Health care workers who had a good knowledge score were 2.28 times more likely to have good infection prevention practices compared to those who had poor knowledge scores (AOR=2.61 $(1.48,4.62)$ ) (Table 5).

\section{Discussion}

The finding of this study demonstrated that the greater part (93.3\%) of the study participant had selfreported good knowledge towards COVID-19. Findings are consistent with a study in District 2 Hospital, Ho Chi Minh (98.2\%) (19), a study in Pakistan (93.2\%) (21), and the finding from China (89\%) (22). This high percentage of knowledge about COVID-19 among healthcare workers is due to prolonged exposure to information since its global topic of discussion on the media and public. Another reason could be the effort of government and media in providing information starting from the time of the outbreak.

The study further showed that $64.2 \%$ of the study participants had self-reported good infection prevention practices towards COVID-19. This finding is in an agreement with the study in Northern Ethiopia among nurses in which $67 \%$ had good infection prevention practice towards the COVID-19(23) but lower than the finding of a study from Makerere University Teaching Hospitals, Uganda that showed $74 \%$ of the study participants demonstrated good practice towards COVID-19 prevention(20). The possible reason for the current low practice might be due to variation in the cut of point which is used to determine the outcome variable and variation in type and number of healthcare facilities included in these studies.

The study further revealed that HCWs perceived overcrowding in the emergency room and limited availability of infection prevention material as the major barriers to infection prevention practice. This finding is supported by the study in Pakistan where overcrowding in emergency rooms and limited infection control material were the major barriers in infection control practice (21).

On multivariable logistic regression analysis, gender, educational status, profession, years of service, Knowledge, and availability of personal protective equipment were significantly associated with good infection prevention practices. Accordingly, male HCWs were more likely to have good infection prevention practices than female health care workers. This study is supported by a study among health care workers in selected hospitals that revealed male HCWs promoted IPC behavior compared to females(24).

Healthcare workers having bachelor's degrees were more likely to have good infection prevention practices compared to diploma holders. The finding from a study at Makerere University Teaching Hospital, Uganda in which holding a diploma is significantly associated with good practices contradicts this study finding(20). This difference could be attributed to the difference in workload of staff wherein our study the degree holders might be overburdened with different responsibilities. 
The health workers' profession was another factor significantly associated with infection prevention practices. Physicians were more likely to practice infection prevention than nurses. This difference could be due to disparities of knowledge among HCWs. Doctors are actively involved in seeking information due to their active roles in improving treatment outcomes of patients with COVID-19. This finding is inconsistent with another study conducted in Pakistan in which Pharmacists were more likely to practice infection prevention practice(21).

The study revealed that service year was significantly associated with infection prevention practice. Healthcare workers having longer years of service were more likely to have good infection prevention practices compared to those who have served for less than five years. This finding is in line with the finding of the study conducted in Pakistan that revealed experienced ( $>5$ years) HCWs were more likely to follow precautionary practices(21). The possible explanation is that experienced workers have skills and experience in dealing with public health emergencies.

Knowledge of the health care workers towards COVID-19 was significantly associated with infection prevention practice. Healthcare workers who had self-reported good knowledge were more likely to have self-reported good practice scores towards COVID-19 than those who had poor knowledge. This finding is supported by a study finding from Chitwan, Nepal that revealed higher knowledge scores were significantly associated with higher practice scores(25).

The study revealed that the availability of personal protective equipment at the work unit was significantly associated with good infection prevention practices towards COVID-19. In contrary to this study, finding from a study among Orthopedic Surgeons in Wuhan, People's Republic of China revealed that insufficient supply of PPE was not associated with Exposures and the COVID-19 Morbidity(26). This difference could be due to the difference in the supply of personal protective equipment and study settings.

The limitation of this study is that the knowledge level and preventive practice of HCWs may be overestimated, as the HCWs might have answered the questions in a way that they believed was socially acceptable rather than being completely accurate. To make the self-reported compliance closer to the actual, the authors devoted all the staff in the research group and trained carefully, to orient the HCWs to complete the questionnaires based on the actual situation.

\section{Conclusions}

The study revealed that $93.3 \%$ of the HCWs had sufficient knowledge towards COVID-19 symptoms, risk conditions, prognosis, modes of transmission and safety, and precautions. There was no statistically significant difference in the level of knowledge about COVID- 19 among health care workers for their age, gender, education level professions, or qualifications. Despite the high knowledge level, the preventive practice towards the COVID-19 was relatively low. Overcrowding in the emergency room, insufficient training on infection prevention, and limited availability of infection prevention equipment was the perceived barrier to infection prevention practices. Gender, educational status, profession, year of service, 
knowledge towards COVID-19, and availability of personal protective equipment were significantly associated with the good infection prevention practices. Hence, education intervention and campaigns are required for HCWs to improve their preventive practices, and optimizing the infection prevention and control loop of the health facilities is recommended.

\section{Abbreviations}

AOR Adjusted odds ratio

ART Anti-Retro Viral

COR Crude Odds ratio

COVID-19 Corona Virus Disease 2019

$\mathrm{FMOH} \quad$ Federal Ministry of Health

HAI Healthcare Acquired Infections

HCFs Health Care Facilities

HCWs Health Care Workers

IPC Infection Prevention and Control

$\mathrm{MCH} \quad$ Mother and Child Health

OPD Out Patient Department

PHEIC Public Health Emergency of International Concern

PPE Personal Protective Equipment

SD Standard deviation

SARS-CoV Severe Acute Respiratory Syndrome Coronavirus

WASH Water, Sanitation and Hygiene

WHO World Health Organizations

\section{Declarations}

\section{Ethics approval and consent to participate}


The study was conducted following the Declaration of Helsinki. Ethical clearance was obtained from the Ethical review committee of Mettu University. The purpose and significance of the study were explained to each participant. Written informed consent was obtained from each study participant before they filled in the questionnaire, and participants' involvement was only voluntary. Participants who were not willing to participate and want to resign at any step of filling the questionnaire were informed to do so without any restriction. Names of participants were not included in the questionnaire, and the confidentiality of the data was kept at all levels of the study. The supervisors and facilitators wore a face mask and maintained a minimum distance of two meters. They also used alcohol-based hand sanitizers before handing and receiving the questionnaire to/from the study participants.

\section{Consent to publish}

Not applicable

\section{Availability of data and materials}

To keep respondents' confidentiality, the raw data would not be shared. But, it is available from the corresponding author on reasonable request and the summary data are available in the main document. The tool was attached as an additional file.

\section{Competing interests}

The authors assert that they have no opposing interests.

\section{Funding}

Limited funding was received from Mettu University to support the travel and data collection expenses.

\section{Role of funding sources}

The views presented in this article are of the authors and do not necessarily express the views of the sponsoring organization. Mettu University did not involve in the data collection, analysis, and interpretation of the results.

\section{Authors' Contributions}

MS, DO, SD, GB, KB, and DT conceived the idea for the study, designed the study, developed the analysis parameters and collected the data. MS, DO, SD, GB, KB, and DT were involved in the analysis and interpretation of the findings. DT produced the initial draft of the paper and MS, DO, SD, GB, and KB provided contributions to various sections. All authors read and approved the final manuscript.

\section{Acknowledgments}

We would like to express our sincere appreciation to Mettu University, Illu Aba Bor, and Bunno Bedelle Zone health departments, respective district health offices, and health facilities. We would also like to 
thank the data facilitators and study participants and all others involved in any process of the study.

\section{References}

1. Wang C, Horby PW, Hayden FG et al. L. A novel coronavirus outbreak of global health concern. Lancet. 2020;395(10223):470-3.

2. Nishiura H. The Extent of Transmission of Novel Coronavirus in Wuhan, China. J Clin Med. 2020;9(330).

3. China Daily. Over 22,000 healthcare workers are infected by COVID-19. Vol. 2020.

4. The Lancet. COVID-19: protecting health-care workers. Lancet. 2020;395(10228):922.

5. Petersen E, Hui D, Hamer DH, Blumberg L, Madoff LC, Pollack M et al. LW. a face to the frontline healthcare worker. The first doctor to notify the emergence of the SARS-CoV-2, (COVID-19), outbreak. Int J Infect Dis. 2020;93:205-7.

6. World Health Organization. COVID-19 cases top 10000 in Africa. [Internet]. 2020. Available from: Accessed April 2020.

7. UNICEF. ETHIOPIA COVID-19 Situation Report No 3. 2020.

8. UNICEF. ETHIOPIA COVID-19 Situation Report No 6. 2020.

9. Chan JF, Yuan S, Kok KH et al. A familial cluster of pneumonia associated with the 2019 novel coronavirus indicating person-to-person transmission: a study of a family cluster. Lancet. 2020;395(10223):514-23.

10. WHO. Health workers exposure risk assessment and management in the context of the COVID-19 virus. 2020;1-8.

11. El Bushra HE AA. The outcome of the strict implementation of infection prevention control measures during an outbreak of Middle East respiratory syndrome. Am J Infect Control. 2017;45(5):502-7.

12. ljarotimi IT, llesanmi OS AA. Knowledge of Lassa fever and use of infection prevention and control facilities among health care workers during the Lassa fever outbreak in Ondo State, Nigeria. Pan Afr Med J. 2018;30(56).

13. Belfroid E, Van Steenbergen J TA. Preparedness and the importance of meeting the needs of healthcare workers: a qualitative study on Ebola. J Hosp Infect. 2017;98:212-8.

14. Fix GM, Reisinger HS EA. Health care workers' perceptions and reported use of respiratory protective equipment: A qualitative analysis. Am J Infect Control. 2019;47(10):1162-6.

15. Yen MY, Lu YC HP. Quantitative evaluation of infection control models in the prevention of nosocomial transmission of SARS virus to healthcare workers: implication to nosocomial viral infection control for healthcare workers. Scand J Infect Dis. 2010;42(6):510-5.

16. WHO/UNICEF. Water, sanitation, hygiene, and waste management for the COVID-19 virus: interim guidance. March 19, 2020. (accessed April 30, 2020).

17. WHO. Revised injection safety assessment tool (tool c-revised). 2008. 
18. WHO. WHO Guidelines on Hand Hygiene in Health Care. 2009.

19. Giao H, Thi N, Han N, Khanh T Van, Ngan VK, Tam V Van, et al. Knowledge and attitude toward COVID-19 among healthcare workers at Knowledge and attitude toward COVID-19 among healthcare workers at District 2 Hospital, Ho Chi Minh City. Asian Pac J Trop Med. 2020;13:1-6.

20. Olum R, Bongomin F. Coronavirus Disease-2019: Knowledge, Attitude, and Practices of Health Care Workers at Makerere University Teaching Hospitals, 2020;8(181):1-9.

21. Saqlain M, Munir MM, Rehman SU, Gulzar A, Naz S, Ahmed Z, et al. Knowledge, attitude, practice and perceived barriers among healthcare workers regarding COVID-19: a cross-sectional survey from Pakistan. J Hosp Infect. 2020;105:419-23.

22. Zhang M, Zhou M, Tang F, Wang Y, Nie H, Zhang L, et al. Knowledge, attitude, and practice regarding COVID-19 among healthcare workers in Henan, China. J Hosp Infect. 2020;105:183-7.

23. Tadesse DB. Knowledge, Attitude, Practice, and Psychological response toward COVID-19 among Nurses during the COVID-19 outbreak in Northern Ethiopia, 2020. 2020;1-14.

24. Lai X, Wang X, Yang Q, Xu X, Tang Y, Liu C, et al. Will healthcare workers improve infection prevention and control behaviors as COVID-19 risk emerges and increases, in China? 2020;1:1-9.

25. Richa Nepal Sapkota, Kalyan, Kalidas Adhikari, Paudel P, Adhikari B, Paudyal N, Sapkota K. Knowledge, attitude and practice regarding COVID-19 among healthcare workers in Chitwan, Nepal. 2020;1-23.

26. Guo X, Wang J, Hu D, Wu L, Gu L, Wang Y, et al. Survey of COVID-19 Disease Among Orthopaedic Surgeons in Wuhan, People's Republic of China. 2020;102:847-54.

\section{Tables}

Table 1: Socio-demographic characteristics of the Healthcare workers in Illu Aba Bor and Buno Bedelle Zones, Southwest Ethiopia, 2020. 


\begin{tabular}{|c|c|c|c|}
\hline Variables & Category & Frequency & Percent \\
\hline \multirow[t]{3}{*}{ Age in years } & $<25$ & 84 & 25.5 \\
\hline & $25-35$ & 185 & 56.1 \\
\hline & $>35$ & 61 & 18.4 \\
\hline \multirow[t]{2}{*}{ Sex } & Male & 203 & 61.5 \\
\hline & Female & 127 & 38.5 \\
\hline \multirow[t]{3}{*}{ Marital status } & Single & 96 & 29.1 \\
\hline & Married & 229 & 69.4 \\
\hline & Others* & 5 & 1.5 \\
\hline \multirow[t]{4}{*}{ Religion } & Orthodox & 109 & 33.0 \\
\hline & Muslim & 57 & 17.3 \\
\hline & protestant & 157 & 47.6 \\
\hline & Others & 7 & 2.1 \\
\hline \multirow[t]{4}{*}{ Ethnicity } & Oromo & 290 & 87.9 \\
\hline & Amhara & 26 & 7.9 \\
\hline & Tigray & 6 & 1.8 \\
\hline & Others** & 8 & 2.4 \\
\hline \multirow[t]{3}{*}{ Educational status } & Diploma & 144 & 43.6 \\
\hline & Degree & 176 & 53.3 \\
\hline & Masters & 10 & 3.03 \\
\hline \multirow[t]{6}{*}{ Profession } & Physician & 29 & 8.8 \\
\hline & Nurse & 184 & 55.8 \\
\hline & Midwife Nurse & 57 & 17.3 \\
\hline & Health officer & 20 & 6.1 \\
\hline & Lab.Technicians & 22 & 6.7 \\
\hline & Pharmacy professional & 18 & 5.5 \\
\hline \multirow[t]{3}{*}{ Years of service } & $<5$ years & 133 & 40.3 \\
\hline & $5-10$ years & 108 & 32.7 \\
\hline & $>10$ years & 89 & 27.0 \\
\hline
\end{tabular}

* Divorced/Widowed

**Wakefata

Table 2: Training and availability of hygiene facilities at Health care facilities of Illu Aba Bor and Bunno Bedelle Zones, Southwest Ethiopia, 2020 


\begin{tabular}{|c|c|c|c|}
\hline Variables & Category & Frequency & Percent \\
\hline \multirow[t]{2}{*}{ Ever had training on infection prevention } & Yes & 135 & 40.9 \\
\hline & No & 195 & 59.1 \\
\hline \multirow{2}{*}{ Infection control program at the institution } & Yes & 153 & 46.4 \\
\hline & No & 177 & 53.6 \\
\hline \multirow[t]{2}{*}{ Infection control team at facility } & Yes & 139 & 39.1 \\
\hline & No & 201 & 60.9 \\
\hline \multirow{2}{*}{$\begin{array}{l}\text { Emerging infectious diseases taskforce (dealing with } \\
\text { outbreaks) available }\end{array}$} & Yes & 154 & 46.5 \\
\hline & No & 180 & 54.5 \\
\hline \multirow{2}{*}{ IPC policies and guidelines available } & Yes & 150 & 45.5 \\
\hline & No & 180 & 54.5 \\
\hline \multirow[t]{2}{*}{ Water facility available } & Yes & 217 & 65.8 \\
\hline & No & 113 & 34.2 \\
\hline \multirow[t]{2}{*}{ Alcohol/hand sanitizer available at facility } & Yes & 248 & 75.2 \\
\hline & No & 82 & 24.8 \\
\hline \multirow[t]{2}{*}{ Adequate soap at work unit } & Yes & 150 & 45.5 \\
\hline & No & 180 & 54.5 \\
\hline \multirow[t]{2}{*}{ Adequate disinfectants available at work unit } & Yes & 145 & 43.9 \\
\hline & No & 185 & 56.1 \\
\hline \multirow[t]{2}{*}{ Sufficient PPE available } & Yes & 109 & 33.0 \\
\hline & No & 221 & 67.0 \\
\hline \multirow[t]{2}{*}{ Have safety box for sharp disposal } & Yes & 243 & 73.6 \\
\hline & No & 87 & 26.4 \\
\hline \multirow{2}{*}{$\begin{array}{l}\text { Working unit has colored dust bin to segregate } \\
\text { medical wastes }\end{array}$} & Yes & 140 & 42.4 \\
\hline & No & 190 & 57.6 \\
\hline \multirow[t]{12}{*}{ Currently assigned place(ward) } & OPD & 128 & 38.8 \\
\hline & Laboratory & 35 & 10.6 \\
\hline & Pharmacy & 23 & 7.0 \\
\hline & Medical & 22 & 6.7 \\
\hline & ward & 13 & 3.9 \\
\hline & Surgical & 12 & 3.6 \\
\hline & ward & 12 & 3.6 \\
\hline & Paediatric & 43 & 13.0 \\
\hline & ward & 42 & 12.7 \\
\hline & TB and & & \\
\hline & ART & & \\
\hline & $\begin{array}{l}\text { MCH } \\
\text { GYN \& OBS }\end{array}$ & & \\
\hline
\end{tabular}

IPC- Infection prevention and control OPD - Out patient department $\mathrm{MCH}$ - Mother and child Health
TB - Tuberculosis

ART - Anti retro viral therapy

PPE - Personal protective equipment

Table 3 Knowledge towards COVID-19 among healthcare workers of Illu Aba Bor and Buno Bedelle Zones, Southwest Ethiopia, 2020 


\begin{tabular}{|c|c|c|c|}
\hline Knowledge questions & Category & Number & Percent \\
\hline \multirow[t]{2}{*}{ COVID-19 is a virus infection } & Yes & 320 & 97 \\
\hline & No & 10 & 3.0 \\
\hline \multirow{2}{*}{$\begin{array}{l}\text { COVID-19 is transmitted by close contact with the infected } \\
\text { person }\end{array}$} & Yes & 300 & 90.9 \\
\hline & No & 30 & 9.1 \\
\hline \multirow[t]{2}{*}{ Know common modes of transmission } & Yes & 322 & 97.6 \\
\hline & No & 8 & 2.4 \\
\hline \multirow[t]{2}{*}{ The incubation period is 14 days } & Yes & 253 & 76.7 \\
\hline & No & 77 & 23.3 \\
\hline \multirow{2}{*}{$\begin{array}{l}\text { Fever, cough, sore throats and shortness breath are } \\
\text { common symptoms of COVID-19 }\end{array}$} & Yes & 323 & 97.9 \\
\hline & No & 7 & 2.1 \\
\hline \multirow[t]{2}{*}{ The isolation period is two weeks } & Yes & 291 & 88.2 \\
\hline & No & 39 & 11.8 \\
\hline \multirow[t]{2}{*}{ COVID-19 vaccine is available on markets } & Yes & 67 & 20.3 \\
\hline & No & 263 & 79.7 \\
\hline \multirow[t]{2}{*}{ Antibiotics are the first-line treatment } & Yes & 98 & 29.7 \\
\hline & No & 232 & 70.3 \\
\hline \multicolumn{4}{|l|}{ Frequent hands wash with soap and water or alcohol- } \\
\hline $\begin{array}{l}\text { based hand rub and using face masks can help in the } \\
\text { prevention of disease transmission }\end{array}$ & No & 24 & 7.3 \\
\hline \multirow{2}{*}{$\begin{array}{l}\text { Patients with underlying chronic diseases are at a higher } \\
\text { risk of infection and death }\end{array}$} & Yes & 302 & 91.5 \\
\hline & No & 28 & 8.5 \\
\hline \multirow[t]{2}{*}{ Healthcare workers are at a higher risk of infection } & Yes & 311 & 94.2 \\
\hline & No & 19 & 5.8 \\
\hline \multirow[t]{2}{*}{ COVID-19 could be fatal } & Yes & 251 & 76.1 \\
\hline & No & 79 & 23.9 \\
\hline \multirow[t]{2}{*}{ Knowledge } & Poor & 22 & 6.7 \\
\hline & Good & 308 & 93.3 \\
\hline \multicolumn{4}{|l|}{ Mean \pm SD knowledge score } \\
\hline Mean \pm SD & \multicolumn{3}{|c|}{$9.04 \pm 1.06$} \\
\hline
\end{tabular}

SD - Standard deviation

Table 4 Test of significance of variation (Independent sample t-test and one way ANOVA) in knowledge score by socio-demographic characteristics, Illu Aba Bor and Buno Bedelle Zones, Southwest Ethiopian, 2020. 


\begin{tabular}{|c|c|c|c|c|}
\hline Variables & $\begin{array}{c}\text { Mean( }(\mathrm{SD}) \\
\text { Knowledge }\end{array}$ & t-test & F-test & P-value \\
\hline Age in years & & & 3.013 & 0.050 \\
\hline$<25$ & $8.79 \pm 1.27$ & & & \\
\hline $25-35$ & $9.13 \pm 0.96$ & & & \\
\hline$>35$ & $9.08 \pm 0.94$ & & & \\
\hline Sex & & 1.073 & & 0.284 \\
\hline Male & $9.05 \pm 1.13$ & & & \\
\hline Female & $8.93 \pm 1.34$ & & & \\
\hline Educational status & & & 0.679 & 0.508 \\
\hline Diploma & $8.96 \pm 1.22$ & & & \\
\hline Degree & $9.09 \pm 0.90$ & & & \\
\hline Masters & $9.20 \pm 1.03$ & & & \\
\hline Profession & & & 0.543 & 0.744 \\
\hline Nurse & $9.01 \pm 1.08$ & & & \\
\hline Physician & $8.96 \pm 1.45$ & & & \\
\hline Midwife Nurse & $9.11 \pm 0.84$ & & & \\
\hline Health officer & $9.25 \pm 0.72$ & & & \\
\hline Lab.Technicians & $8.83 \pm 1.42$ & & & \\
\hline Pharmacy professional & $9.03 \pm 1.05$ & & & \\
\hline Years of service & & & 2.361 & 0.096 \\
\hline$<5$ years & $8.89 \pm 1.19$ & & & \\
\hline $5-10$ years & $9.18 \pm 0.89$ & & & \\
\hline$>10$ years & $9.04 \pm 1.05$ & & & \\
\hline
\end{tabular}

SD - Standard deviation

Table 5 Multivariable logistic regression analysis of factors associated with infection prevention practice among HCWs in Illu Aba Bor and Bunno Bedelle Zones, Southwest Ethiopia, 2020. 


\begin{tabular}{|c|c|c|c|c|c|}
\hline \multirow[t]{2}{*}{ Characteristics } & \multirow[t]{2}{*}{ Category } & \multicolumn{2}{|c|}{ IPC Practice } & \multirow[t]{2}{*}{ COR(95\%CI) } & \multirow[t]{2}{*}{ AOR(95\%CI) } \\
\hline & & $\begin{array}{c}\text { Good } \\
\text { N (\%) }\end{array}$ & $\begin{array}{c}\text { Poor } \\
\text { N (\%) }\end{array}$ & & \\
\hline Sex & $\begin{array}{l}\text { Male } \\
\text { Female }\end{array}$ & $\begin{array}{c}148(72.9) \\
64(50.4)\end{array}$ & $\begin{array}{l}55(27.1) \\
63(49.6)\end{array}$ & $\begin{array}{c}3.28(1.83,5.87) \\
1.00\end{array}$ & $\begin{array}{c}3.65(1.96,6.80)^{* *} \\
1.00\end{array}$ \\
\hline $\begin{array}{l}\text { Educational } \\
\text { status }\end{array}$ & $\begin{array}{l}\text { Diploma } \\
\text { Degree } \\
\text { Masters }\end{array}$ & $\begin{array}{c}82(56.9) \\
124(70.5) \\
6(60.0)\end{array}$ & $\begin{array}{c}62(43.1) \\
52(29.5) \\
4(40.0)\end{array}$ & $\begin{array}{c}1.00 \\
1.80(1.14 \\
2.86) \\
1.13(0.31 .4 .19)\end{array}$ & $\begin{array}{c}1.00 \\
1.82(1.02,3.22)^{*} \\
1.42(0.31,6.39)\end{array}$ \\
\hline Profession & $\begin{array}{l}\text { Nurse } \\
\text { Physician } \\
\text { Midwife } \\
\text { nurse } \\
\text { Health }\end{array}$ & $\begin{array}{l}109(59.2) \\
23(79.3) \\
39(68.4) \\
16(80.0) \\
16(72.7)\end{array}$ & $\begin{array}{c}75(40.8) \\
6(20.7) \\
18(31.6) \\
4(20.0) \\
6(27.3)\end{array}$ & $\begin{array}{c}1.00 \\
0.38(0.15 .0 .98) \\
0.57(0.19,1.63) \\
1.04(0.25,4.30) \\
0.69(0.19,2.55)\end{array}$ & $\begin{array}{c}1.00 \\
3.17(1.08,9.33) * \\
1.64(0.77,3.49) \\
2.42(0.70,8.37) \\
0.83(0.27,2.60)\end{array}$ \\
\hline & $\begin{array}{l}\text { Lab } \\
\text { Technicians } \\
\text { Pharmacy } \\
\text { professional }\end{array}$ & $9(50.0)$ & $9(50.0)$ & $0.26(0.07,0.95)$ & $0.52(0.17,1.59)$ \\
\hline $\begin{array}{l}\text { Years of } \\
\text { service }\end{array}$ & $\begin{array}{l}<5 \\
5-10 \\
>10\end{array}$ & $\begin{array}{l}77(57.9) \\
75(69.4) \\
60(67.4)\end{array}$ & $\begin{array}{l}56(42.1) \\
33(30.6) \\
29(32.6)\end{array}$ & $\begin{array}{c}1.00 \\
1.65(0.972 .82) \\
1.51(0.86,2.64)\end{array}$ & $\begin{array}{c}1.00 \\
2.00(1.02,3.92)^{*} \\
3.14(1.51,6.52)^{*}\end{array}$ \\
\hline Knowledge & $\begin{array}{l}\text { Poor } \\
\text { Good }\end{array}$ & $\begin{array}{c}10(45.5) \\
202(54.5)\end{array}$ & $\begin{array}{c}12(65.6) \\
106(34.4)\end{array}$ & $\begin{array}{c}1.00 \\
2.29(0.96,5.47)\end{array}$ & $2.35(1.56,4.98) *$ \\
\hline $\begin{array}{l}\text { Training on } \\
\text { IPC }\end{array}$ & $\begin{array}{l}\text { Yes } \\
\text { No }\end{array}$ & $\begin{array}{c}95(70.4) \\
117(60.0)\end{array}$ & $\begin{array}{l}40(29.6) \\
78(40.0)\end{array}$ & $\begin{array}{c}1.58(0.99,2.53) \\
1.00\end{array}$ & $\begin{array}{c}1.54(0.87,2.72) \\
1.00\end{array}$ \\
\hline $\begin{array}{l}\text { Active IPC } \\
\text { team }\end{array}$ & $\begin{array}{l}\text { Yes } \\
\text { No }\end{array}$ & $\begin{array}{c}93(72.1) \\
119(59.2)\end{array}$ & $\begin{array}{l}36(27.9) \\
82(40.8)\end{array}$ & $\begin{array}{c}1.78(1.11,2.87) \\
1.00\end{array}$ & $\begin{array}{c}0.98(0.52,1.84) \\
1.00\end{array}$ \\
\hline IPC policy & $\begin{array}{l}\text { Yes } \\
\text { No }\end{array}$ & $\begin{array}{l}108(72.0) \\
104(57.8)\end{array}$ & $\begin{array}{l}42(28.0) \\
76(42.2)\end{array}$ & $\begin{array}{c}1.88(1.18,2.99) \\
1.00\end{array}$ & $\begin{array}{c}1.21(0.66,2.35) \\
1.00\end{array}$ \\
\hline $\begin{array}{l}\text { Availability of } \\
\text { Water }\end{array}$ & $\begin{array}{l}\text { Yes } \\
\text { No }\end{array}$ & $\begin{array}{l}149(68.7) \\
63(55.8)\end{array}$ & $\begin{array}{l}68(31.3) \\
50(44.2)\end{array}$ & $\begin{array}{c}1.74(1.09,2.78) \\
1.00\end{array}$ & $\begin{array}{c}1.26(0.72,2.20) \\
1.00\end{array}$ \\
\hline $\begin{array}{l}\text { Availability of } \\
\text { hand sanitizer }\end{array}$ & $\begin{array}{l}\text { Yes } \\
\text { No }\end{array}$ & $\begin{array}{c}168(67.7) \\
44(53.7)\end{array}$ & $\begin{array}{l}80(32.3) \\
38(46.3)\end{array}$ & $\begin{array}{c}1.81(1.09,3.02) \\
1.00\end{array}$ & $\begin{array}{c}0.99(0.54,1.81) \\
1.00\end{array}$ \\
\hline $\begin{array}{l}\text { Availability of } \\
\text { PPE }\end{array}$ & $\begin{array}{l}\text { Yes } \\
\text { No }\end{array}$ & $\begin{array}{l}85(78.7) \\
127(57.2)\end{array}$ & $\begin{array}{l}23(21.3) \\
95(42.8)\end{array}$ & $\begin{array}{c}2.76(1.62,4.71) \\
1.00\end{array}$ & $\begin{array}{c}1.96(1.06,3.61)^{*} \\
1.00\end{array}$ \\
\hline
\end{tabular}

$* *$ Significant at $<0.01$.

COR: crude odds ratio;

HCW - Health care worker
*Significant at< 0.05 .

IPC - Infection prevention practice AOR: adjusted odds ratio; PPE: Personal protective equipment

\section{Figures}




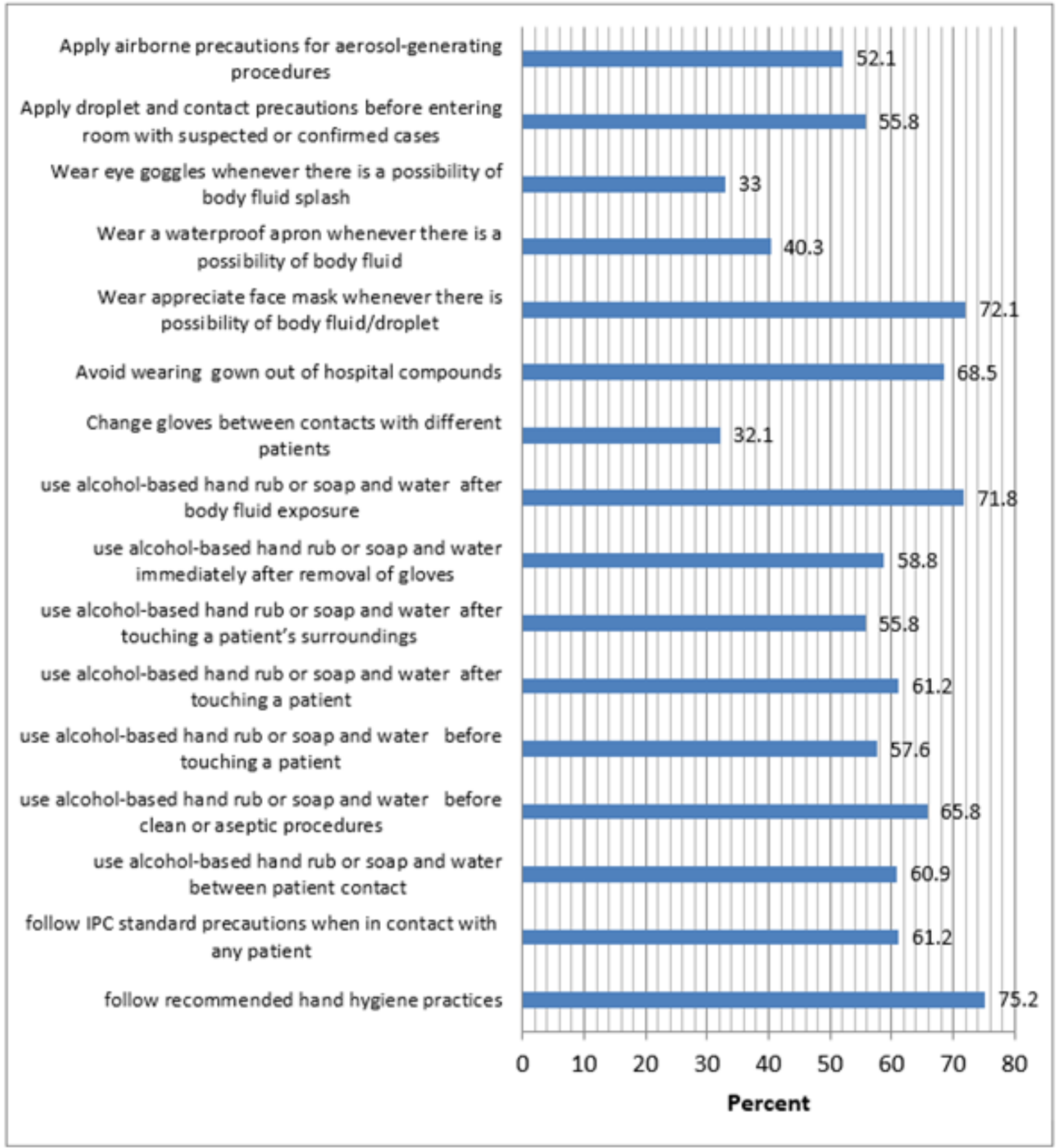

\section{Figure 1}

COVID-19 preventive practices among HCWs in Illu Aba Bor and Bunno Bedelle Zones, Southwest Ethiopia, 2020 


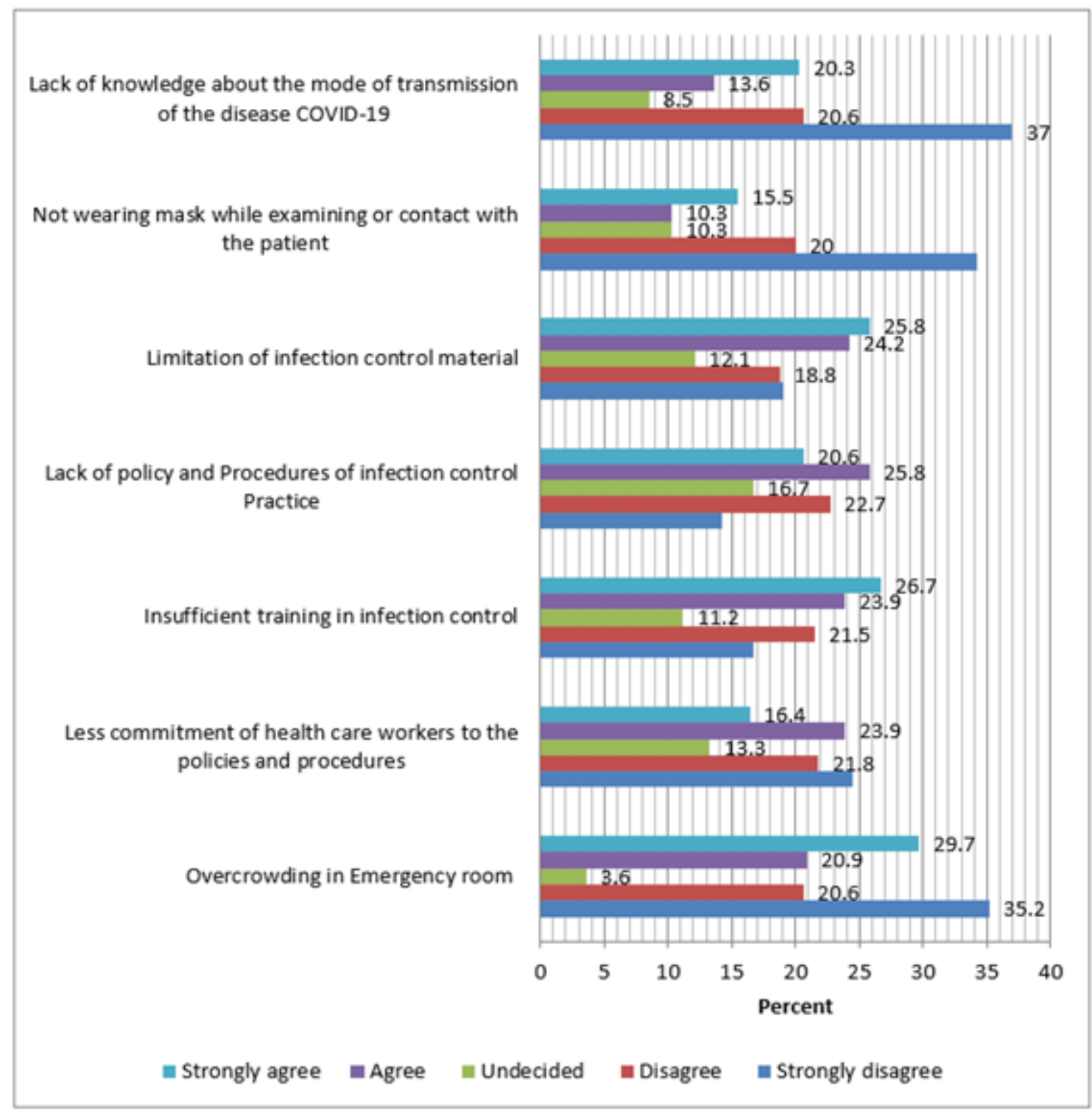

Figure 2

Perceived barriers to infection prevention practice toward COVID-19 by the study participants, Illu Aba Bor and Buno Bedelle Zones, Southwest Ethiopia, 2020. 